\title{
DE PLAATS VAN STEEKPROEVEN IN HET CONTROLEPROGRAMMA VAN DE ACCOUNTANT
}

\author{
door Prof. Dr. A. Mey
}

\section{Rechtzetting van een misverstand}

In het naar de feitelijke inhoud - ondanks meningsverschil - door mij gewaardeerde artikel van de heer A. van Heerden in het nummer van december 1961 komt op pagina's 456 en 457 een passage voor, die mij aanleiding geeft tot de navolgende opmerkingen. ${ }^{1}$ )

De heer Van Heerden slaat aan op mijn artikel in het voorafgaand septembernummer, waarin het betoog van collega De Wolff in Statistica Neerlandica van 1956 en 1959, inzake gelaagde steekproeven in de accountantscontrole wordt besproken. In dit laatste artikel wordt de betekenis van deze methode gepresenteerd als ,produktiviteitsverhoging”. Het lijkt mij dat aan de heer Van Heerden ontgaan is, dat mijn bezwaar zich in hoofdzaak richt tegen deze aandiening: „produktiviteitsverhoging" van ons controlewerk. Een effect, dat ik in de volle betekenis van het woord - naar gezegd in de ,inleiding en probleemstelling" van het september-artikel - beperkt zie tot de gevallen, waarin de accountant in de functie van facultatief-aanwezig-intern controleur, de accuratessecontrole in het door hem gecontroleerde bedrijf moet verzorgen. In deze opmerking ligt reeds een tegenspraak tot de kritiek van de heer Van Heerden op mijn artikel.

De opmerkingen van deze auteur voeren tot de conclusie dat in een miskenning mijnerzijds van de methode van mijn collega, ,,de grondslag ligt voor de (mijn) eindconclusie, die de methode De Wolff terugwijst tot een heldere formulering van iets wat wij al lang wisten".

Dit is echter bedoeld noch gezegd. De misverstane weergave van mijn woorden moge ik recht zetten. Ik kan dit niet op mij laten zitten, omdat wel weinig lezers de tijd zullen hebben om mijn artikel van september 1961 na te slaan ten einde te onderzoeken of ik dit zo gezegd heb en of dit mijn bedoeling geweest kan zijn. Ik moet dus nu zeggen, wat ik liever als naschrift direct na het artikel van Van Heerden verteld zou hebben.

De laatste zin van de conclusie van mijn artikel (pag. 324) is: „Erken ik dus niet het etiket, waaronder statisticus Prof. de Wolff ons zijn methode aanbiedt; ik erken, dat hij met zijn uiteenzetting op heldere wetenschappelijke wijze de betekenis heeft getoond van een werkmethode voor een deel van het controleprogramma, welke wij te veel op ervaringsgrondslagen alleen hebben toegepast".

Mijn toon is dus anders dan de mineur-transpositie in des heren Van Heerden's weergave.

In het onmiddellijk aan deze woorden voorafgaande komt weer uit, dat het mij er om gaat te voorkomen dat de steekproeven-methode in de accountantscontrole een grotere plaats gaat innemen dan haar thans naar veler vakkundig oordeel toekomt. Een plaats, die zij in voorafgaande decennia heeft gehad en in veel van de buitenlandse literatuur in de praktijk nog heeft. Onmiddellijk aan de door de heer Van Heerden geciteerde in mineur getransporteerde slotzin gaan vooraf de woorden: „Steekproeven leveren nooit een in kringloop gesloten con-

1) Wat het probleem aangaat sta ik dichter bij de opvatting van Drs. H. A. J. F. Misset in het april-nummer van dit maandschrift. 
troleprogramma. $Z_{i j}$ doen dit evenmin als een volledig afchecken van alle boekingen met bescheiden en andere boeken". Ik geloof niet aan een thans nog in te voeren „produktiviteitsverhoging door steekproeven, tenzij men dit zou stellen tegenover het allcheck-systeem, dat ik in 1936 al bevochten heb; hetgeen in de praktijk overigens toch nog - dank zij slecht georganiseerde boekhoudingen - een taai leven blijkt te hebben". Dit houdt in dat de steekproeven in wat men administratieve controle noemt (wel te onderscheiden van accountantscontrole), als toetsingsmiddel van de werking der voorschriften tot creëren van interne controle, niet gemist kunnen worden. Dit heb ik gezegd in het september-artikel pag. 319 van de vorige jaargang. Bovendien staat dit te lezen in veel van mijn vroegere geschriften over dit onderwerp. Het werd menigmaal uitgesproken in de capita selecta der controleleer.

In de aanvang van het artikel herhaal ik een - vele malen door mij gedane uitspraak, dat steekproeven onder vereiste condities en op de juiste wijze toegepast, nooit door mij - noch door mijn vrienden in de bouw der techniek van accountantscontrole - bestreden zijn, „mits onder vereiste condities en op de juiste wijze toegepast”. „Zij zijn aanvaard als organisch deel van de zelfstandige actie, die in de juiste orchestrering van alle controle-instrumenten ligt".

Misschien is mijn vrees toch niet geheel ten onrechte, dat sommigen de „gelaagde steekproeven" een solo-partij willen laten spelen. Mocht van de in de twintiger jaren wel eens besproken medezeggenschap van de opdrachtgever met de controletechniek (uiteraard niet bij grote concerns, maar in kleinere zaken) nog iets bestaan, dan zou de gedachte aan de mogelijke produktiviteitsverhoging - en dus kostenbesparing - een overwonnen standpunt nieuw leven kunnen inblazen.

\section{De vermeende gronden der „miskenning”}

De heer Van Heerden verwijt mij, ,dat mijn beschouwing ten onrechte de verbandscontrole" ten tonele voert als tegenhanger van steekproeven en daarmede de rol aanzienlijk te overschatten die steekproeven zichzelf in de controleleer willen toebedelen". De auteur veroorlove mij hier een literaire correctie van zijn betoog, omdat die in het misverstaan van betekenis is. Het begrip "tegenhanger" past niet in het beeld van de regie van het toneelspel, dat hij gebruikt. Het zou in dit verband alleen een ,tegenspeler" moeten zijn. Steekproeven kunnen zich zelf geen rol toebedelen. Hun wordt een rol toebedeeld door hen, die van die proeven gebruik maken. Mijn vrees is steeds geweest - en daarin meen ik niet alleen te staan - dat er onder controleurs wel zijn, die steekproeven niet onder vereiste condities en op de juiste wijze toepassen. ${ }^{2}$ ) De bedoeling van mijn septemberartikel was nu alleen om aan te tonen, dat daaraan toe te voegen is: op de juiste grondslagen; voorts de grote betekenis te erkennen van De Wolff's methode om tot de juiste grondslagen te komen.

\footnotetext{
2) Daarbij is het de vraag wat men onder steekproeven verstaat. De steekproef, waarbij getracht wordt het beeld van de massa op verkleinde schaal te projecteren, past niet in de accountantscontrole, naar mijn oordeel. De gelaagde steekproef zoals Prof. de Wolff die reeds in 1954 besprak in zijn Bedrijfsstatistiek (pag. 316 en 317) (3e druk) heeft een geheel ander karakter. Zij wordt voorafgegaan door systematische ordening van de te onderscheiden massa naar de graad van belangrijkheid der gevallen. De auteur bespreekt de omzet naar afnemers van verschillend karakter en het onderzoek naar de spreiding rondom de standaarddeviatie. Het boek is verplichte literatuur voor het vak statistiek van het N.I.v.A.-examen.
}

m a b blz. 84 
Wat zie ik als vereiste condities? Allereerst dat het verband in de goederenbeweging (Inkoop grondstoffen - voorraad grondstoffen - verbruik grondstoffen verkregen fabrikaat - verkoop product) vaststaat in technisch-kwantitatieve gegevens. Vervolgens dat de accountant te dien aanzien zijn conclusie niet op het bestaan van interne controle, in voorschriften, enz,. baseert, maar dat hij dit verband ook zelfstandig controleert.

De vraag is nu: kan dat zelfstandig controleren van het verband ook partieel geschieden of moet het onderzoek naar het bestaan van dit verband tot alle goederen worden uitgestrekt? Mijn opvatting is steeds geweest dat de accountant zich ten deze, in vele gevallen en bij goed georganiseerde administratie, kan beperken tot die goederen, materialen of grondstoffen, welke in het bijzonder voor dat verband karakteristiek zijn of wel tot die belangrijke goederen of goederengroepen behoren, die het grootste deel der goederenbeweging omspannen.

Ik heb er vaak op gewezen (ook in september 1961), dat zodanige werkmethode een belangrijke beperking van het werk betekent en veelal voldoende zekerheid geeft. Ik wees er bovendien op, dat in fabrieken het verband tussen enerzijds het verbruik van deze (technisch-belangrijke of zeer waardevolle) soort of soorten van materialen of grondstoffen en anderzijds het verbruik van die soorten, die in het productieproces aanvullende betekenis hebben, door in de fabricage bekende verhoudingscijfers kan worden geconstateerd. Aldus ligt - en lag gedurende de jaren van mijn onderwijs in accountancy- de techniek der verbandscontrole.

Ik citeer uit een publicatie van twintig jaar geleden: „De grote betekenis, welke het kwantitatieve moment in de kostprijscalculatie en in de administratie van het productieproces voor de accountantscontrole heeft, springt hier in het oog. Zonder kwantitatieve kostenstandaards kan de accountant - als administratief deskundige - niet alleen de productie niet controleren, maar ook de verkochte hoeveelheden niet vaststellen. Zonder kwantitatieve normen voor materialenverlies, voor mislukking, voor slechte uitval en dergelijken zouden er onbeoordeelbare hiaten in zijn controle blijven, welke onder daartoe geëigende voorwaarden veel ongerechtigs konden verbergen. Met die normen kan dat niet meer. Zijn greep op het bedrijfsgebeuren sluit daardoor aan bij de technische controle op de bedrijfszuinigheid en moge hij als leek op technisch gebied de normen, zoals ze in het bedrijf in kwestie gelden, al moeten aanvaarden, hij is voldoende statisticus om te beoordelen of de frequentie en de amplitude van voorkomende verschillen zodanig is, dat die (zonder twijfel aan de betrouwbaarheid der normen) kunnen worden aanvaard, dan wel een aanwijzing daarin gevonden wordt van iets, dat op een ,lek" zou kunnen wijzen."3)

Ook deze beperking tot de belangrijkste elementen der goederenbeweging berust op ervaring, tevens op cijferbeoordeling en op de beoordeling van de betekenis van die elementen.

De normen van de productie en de toleranties (afhankelijk van verschillende

3) Citaat uit mijn artikel M.A.B. 1942: „Het technisch-kwantitatieve moment in de problemen van de toegepaste bedrijfseconomie"; herdrukt in 25 jaren M.A.B. blz. 194 (blz. 204). In de uitdrukking: ,hij is voldoende statisticus" is wellicht de wens de vader van de gedachte geweest. Misschien ook bedoelde ik met een zekere dosis tactiek de studie van de statistiek voor de a.s. accountant te stimuleren. Een verdergaande studie (op specialisatie gericht) in de statistiek zou naar mijn inzicht voor accountants belangrijk zijn. Daarnaast zullen ook andere specialisaties kunnen optreden, die na de studie voor het N.I.v.A.-diploma kunnen worden opgevat, terwijl een groot deel der afgestudeerden zich tot het bereikte kan beperken. 
oorzaken en voorkomende onder bepaalde omstandigheden) zijn vastgesteld met behulp van statistische analyse. Ik meende (in het artikel in kwestie pag. 323) te mogen constateren, dat naar mijn oordeel, zowel voor dat vaststellen door de interne-technische instanties als voor de controlerende accountant - het benutten van de methode De Wolff belangrijk zou zijn.

De relatie tussen de voor de bepaling van het voor de omvang der productie belangrijke materialenverbruik en het verbruik van de overige materialen moge een technisch gegeven zijn, het cijfer, dat die relatie uitdrukt zal de niet-technisch deskundige accountant moeten testen. Ook ten deze lijkt mij de methode De Wolff een hulpmiddel, dat de accountant in zijn instrumentarium zal moeten opnemen en waarvan hij in de praktijk dankbaar gebruik zal maken. Dat ik amateurlijk reeds deze weg ben opgegaan heb ik gesteld ten bewijze van mijn erkentelijkheid voor het nieuwe instrument, dat vakkundig hanteerbaar is. En zal in vele gevallen het amateurlijk hanteren voldoende zijn, dan heeft de methode het nut om de betrekkelijke doelmatigheid van meer simpele hantering aan te tonen.

Dit alles neemt echter niet weg, dat de kwantitatieve verbandscontrole van input en output n.m.m. de ruggegraat der controle blijft welke in zelfstandige actie is uit te voeren en niet door steekproeven te vervangen is. Dit deel van het onderzoek heeft ook gans ander doel dan dat gericht op aanvaardbaarheid van normen en betekenis van af wijkingen daarvan.

Dit mijn standpunt is niet van vandaag of gisteren; zelfs niet nieuw van 1942. Aldus doceerde ik reeds in de twintiger jaren op de cursus Controleleer van het N.I.v.A.. Ik meen, dat de methode De Wolff het wetenschappelijk bewijs levert voor het door mij langs ervaringsweg ingenomen standpunt. Aldus mijn indruk ook uit De Wolff's boek. De mathematische bewijsvoering in Statistica was mij nieuw en ik ben er de auteur dankbaar voor. In september 1961 is mijn betoog er op gericht geweest te voorkomen dat zij, die aan steekproeven in het controle-programma een grotere betekenis willen toekennen dan aan die methode toekomt, in het betoog van De Wolff - naar ik meen zijns ondanks - steun zouden kunnen vinden.

Er is in de eerste plaats zodanig gevaar denkbaar bij hen, die zich door Vance's steekproeven-theorie aangetrokken voelen. Die zijn er. Althans naar ik meen. Daartegen is eerder geschreven o.m. door Van Rietschoten en door mij. Ik stelde daarom in september 1961 dat - al kan de juiste naleving van voorschriften met steekproeven worden nagegaan, omdat de homogeniteit der daaruit volgende handeling mag worden verondersteld - men dit (n.m.m.) niet zodanig mag uitbreiden, dat de homogeniteit der massa gegarandeerd is, indien de ,,algemeen-erkende regels van het boekhouden zijn toegepast" en men dus de toepassing der steekproeven benut in de verificatie van de boekhoudtechnische handelingen, die in de hulpboeken verantwoord zijn. De Wolff's voorbeeld van de kassier, die fraude pleegde door de boekingen van uitgaven hoger te verantwoorden dan het bedrag van de voucher zou daartoe kunnen leiden. Naar mijn oordeel vallen dergelijke controlehandelingen niet alleen onder de leer der accountantscontrole. Zij behoren eveneens deel uit te maken van de leer der interne controle. Dat die soms door of namens public-accountants in facultatieve aanwezigheid wordt uitgeoefend verandert dit oordeel niet. Dit is in vakkringen wel bekend en erkend. Het werd ook in mijn september-artikel gereleveerd.

In de tweede plaats was er reden om het bovenbedoelde gevaar aanwezig te ach- 
ten in een zinsnede in De Wolff's betoog, welke n.m.m. twee voor accountants niet bijeenhorende zaken identificeerde. Op dit punt meende ik te moeten aanslaan, er daarbij van uitgaande dat De Wolff niet als accountant mijn collega is. Hem zij dus geen verwijt over deze identificatie. Deze auteur zegt daar het volgende: „De particuliere accountant in Nederland baseert de beoordeling van de jaarcijfers van een onderneming niet alleen op een onderzoek naar de kwaliteit van de administratie en van de controle, welke binnen de onderneming plaats vindt, maar ook op een controlesysteem waarin bepaalde administratieve totalen worden gebruikt voor deze toetsing. De juistheid van deze totalen, b.v. het totale bedrag aan uitgaven en de voornaamste componenten daarvan, wordt dikwijls door de externe accountant gecontroleerd, onafhankelijk van de interne controle door de onderneming." Met begrijpelijk bezwaar tegen het woord „dikwijls” in dit verband, sluit ik mij bij deze beschouwing van collega De Wolff aan. Het is een duidelijke beschrijving van de verbandscontrole der totalen, in de zin waarin ik lang en kort geleden (b.v. omtrent verkoopcontrole), de verbandscontrole beschreef. Dat deze verbandscontrole „ten tonele" verscheen is echter niet - zoals de heer Van Heerden zegt - aan mijn regie te danken.

Het betoog van collega De Wolff gaat dan onmiddellijk aansluitend verder en zegt: ,Voor dit doel (de controle van het verband der totalen dus) moeten doorgaans omvangrijke controlewerkzaamheden worden verricht en de vraag is gerezen of het mogelijk is deze onaangename en tijdrovende arbeid te beperken met behulp van doelmatig gekozen steekproefmethoden. Deze vraag kan bevestigend beantwoord worden".

Uit deze uiteenzetting van De Wolff zou men n.m.m. kunnen lezen een pleidooi voor het vervangen van de verbandscontrole der totalen door steekproeven in de hulpboeken. Daartegen richt zich mijn bezwaar.

Het is dus niet mijn beschouwing geweest die een tegenstelling tussen verbandscontrole en controle door steekproeven naar voren brengt. De heer Van Heerden heeft blijkbaar overzien dat het geciteerde stuk op pag. 320 van de vorige jaargang tussen aanhalingstekens staat. Het verheugt mij dan dat hij door zijn aanval de gelegenheid gegeven heeft om de nadruk te leggen op wat in september '61 (pag. 23) door mij is betoogd, dat verbandscontrole (onderzoek naar de geslotenheid van de bedrijfseconomische kringloop als basis voor de bepaling van het resultaat) zodanige betekenis heeft in de controle, dat systematische steekproeven die niet vervangen kunnen.

Ik weet niet of we in de accountantspraktijk reeds geheel uitgegroeid zijn uit het steekproeven nemen zonder voldoende basis, en dus verdergaande dan de vervanging van detailcontrole op punten waar de juistheid van verantwoorde feiten en bedragen reeds in totaal vaststaat. Derhalve mijn betoog (pag. 320) dat langs de wegen der verbandscontrole de homogeniteit van de populatie der administratieve handelingen verzekerd moet zijn, alvorens aan critische steekproeven gedacht kan worden.

Ik meen dat ik in mijn september-artikel voldoende heb laten merken, dat ik met deze opmerking slechts de kans op een verkeerde ontwikkeling uit De Wolff's betoog wilde voorkomen. Evenzo geloof ik voldoende naar voren gebracht te hebben dat voor mij persoonlijk de zinsnede omtrent de mogelijkheid „omvangrijke en onaangename werkzaamheden door doelmatig gekozen steekproeven te beperken" betrekking heef t op gevallen, waarin detailcontrole door de controleur (accountant of administrateur) moest worden toegepast. 
Het instrument van steekproeven, aldus is (ik moge dit herhalen) steeds mijn opvatting geweest in door mij gegeven theoretische beschouwingen, zowel als in praktische toepassingen, kan waardevol zijn om te constateren, dat voorschriften op de juiste wijze werden uitgevoerd, dat toleranties in de normen van fabrikage of in het gewichtsverlies verbonden met opslagduur geen ontoelaatbaarheden tolereren. In mijn betoog van september 1961 blijkt (pag. 323) dat ik het gewenst acht, dat de accountant ook statiscus is, opdat hij aldus beoordelen kan of de normen - buiten het gebied van zijn kennis vallende - door technici vastgesteld door hem kunnen worden aanvaard als grondslagen van zijn werk. De ervaring heeft mij het belang daarvan doen zien.

Ik kan dus in de heer Van Heerden niet anders zien dan een medestander. Immers ook hij ziet - evenals ik - dat steekproeven slechts beperking kunnen opleveren in de gevallen, waarin de controleur - overeenkomstig de controleleer van oordeel is dat zij in zijn programma een constructieve betekenis hebben.

Het is jammer dat de accountant Van Heerden, die naar hij in zijn artikel van december 1961 meedeelt aan de redactie van Prof. de Wolff's artikel heeft medegewerkt, aan dit - naar mijn oordeel voor accountants onduidelijke punt - niet zodanige aandacht gegeven heeft, dat hieruit geen moeilijkheid kon ontstaan. Het is ook jammer, dat hij voor de illustratie van het nut van De Wolff's gelaagde steekproeven niet een voor accountants meer aantrekkelijk voorbeeld heeft geadviseerd.

\section{Miskenning van de methode der gelaagde steekproeven?}

Mijn opponent schrijft: „Het karakter van de gelaagde steekproefmethode wordt voorts miskend, wanneer we zien dat Prof. Mey deze methode analoog beschouwt aan hetgeen hijzelf als afromen betitelt”. „Bij dit laatste wordt getracht door belangrijke delen te controleren een zeer groot percentage van de totaal in het geding zijnde bedragen te omvatten.” „Dit heeft echter slechts de uiterlijke verschijningsvorm met de methode De Wolff gemeen. Hierin is het grensbedrag waarboven men alles controleert slechts middel tot het doel. Of de op deze wijze gecontroleerde posten tezamen een belangrijk deel van het te controleren totaalbedrag uitmaken is daarbij irrelevant en dit deel kan onder bepaalde verhoudingen zelfs zeer gering zijn."

Van miskenning - of onderschatting - van De Wolff's methode is bij mij geen spoor. Laat ik dat vooropstellen. Ik heb getracht bij bezwaar tegen de presentatie als produktiviteitsverhoging van ons werk, de betekenis van de methode, de noodzaak haar te onderwijzen en toe te passen naar voren te brengen. Dit moet echter geschieden aan accountants-studenten onder welke een aantal voor wie de wiskundige problematiek moeilijkheden kan leveren.

De relatie, welke ik gezocht heb tussen wat ik op mijn accountancy-cursussen „afromen” genoemd heb en wat Van Rietschoten ,classificatie"4) noemt zou er toe kunnen dienen om een benadering te vinden.

Afromen moge een ordinaire uitdrukking zijn; bij ons om boter- en kaasproduk-

4) De bron te noemen, zodat mijn aanwijzing geverifieerd kan worden is - al is dit academische mos - achterwege gebleven. Men verlate zich er op dat ik weet, dat mijn collega die term gebruikt heeft. Ik meen dat dit geschiedde tijdens de waarneming van mijn capita-selecta toen ik met een U.N.-missie elders was.

m a b blz. 88 
tie befaamde volk wordt die term ook figuurlijk gebruikt. Afromen kan in lagen geschieden. Classificatie impliceert een stratificatie.

De lezer houde zich overtuigd dat mijn opponent mij ten onrechte verdenkt van de arrogantie mijn pogingen om het gebruik van steekproeven en van de statistische analyse in des accountants werk toe te passen, volkomen gelijk te stellen aan De Wolff's met veel vakmanschap uitgewerkte en gepresenteerde methode. Een zekere parallel geloof ik wel te bestaan. Dat de accountant reeds lang bekend was dat hij, om zekerheid te krijgen van de naleving van een voorschrift, van het blijven binnen een tolerantie in een verbruiksnorm, niet alles behoefde na te checken, mocht (bij alle waardering omtrent de publicatie) niet ongezegd blijven.

De heer Van Heerden ziet de parallel beperkt tot de uiterlijke verschijningsvorm. Deze auteur motiveert dat door te zeggen, dat in de methode De Wolff het irrelevant is of de volledig te controleren posten al dan niet een belangrijk deel van het te controleren totaalbedrag uitmaken. Onder „bepaalde verhoudingen kan dit deel zelfs zeer gering zijn". In de beperking van de controle zoals ik die doceerde zou criterium zijn dat door belangrijke delen te controleren een zeer groot percentage van de total in het geding zijnde bedragen omvat wordt.

Deze kenschetsingen lopen echter niet geheel parallel. Bovendien is - al moge ik wel eens deze typering gebruikt hebben, zoals die zich in vele gevallen presenteert - mijn doel niet gericht op het controleren van een relatief groot deel van het bedrag der goederenbeweging. Het gaat om het constateren (uit het technisch kwantitatief verband van input-output-voorraadmutatie) dat uit gegeven inkopen en bestedingen daarmede verbonden de juistheid van verbruiks- en productieverantwoording en vervolgens de juiste verkoopsverantwoording kunnen worden geconstateerd. Het gaat om het productie-technisch representatieve in de vereiste relatie.

En dit kan bij het stratificeren in de gelaagde steekproevenmethode als goederenbewegingscontrole ook niet gemist worden, naar mijn oordeel.

Grenzen tot hoever het onderzoek gaan moet en hoeveel posten in elke laag in ieder geval te onderzoeken zijn kan men arbitrair trachten vast te stellen. Zulks kan de accountant doen op ervaring zonder de kennis van de methode. Met de methode heeft men t.d. zekerheid van de juistheid van wat men doet. Dat is zeer belangrijk en daarin ligt - naar mijn voorafgaande beschouwing - reeds de grote betekenis van de methode. Of die daarom nu praktisch in alle gevallen toegepast moet worden, wanneer wel, wanneer niet, is een tweede vraag. De grens moet bij beide werkwijzen arbitrair of wetenschappelijk vooraf bepaald worden. Zij is ook hierbij „middel tot het doel”, nl. de best-mogelijke zekerheid te verkrijgen zonder alles ,af te haken”. Men moet vaststellen - aldus heb ik het gezien - waar en in hoeverre het onontdekt blijven van mogelijke fouten of kleine fraudes, voor zij - geaccumuleerd - merkbaar worden, van zodanig gering belang is dat het niet de moeite loont een omvangrijk détail-onderzoek verder voort te zetten. De checkerij - het zij en passant gezegd - houdt trouwens bij alle toewijding der assistenten naar mijn mening een foutkans in, die afchecken in volledige detailcontrole tot een niet volledig betrouwbaar instrument maakt. Derhalve heb ik ook steeds, reeds in de twintiger jaren, getracht het checkwerk te beperken, de interne controle te verstevigen en het zwaartepunt in de verbandscontrole te leggen. De foutkans in het allcheck-werk is naar mij lijkt moeilijk berekenbaar. De Wolff's methode heeft het grote voordeel dat de foutkans berekenbaar is. 
Van de voorheen door mij gedoceerde werkwijze geldt dus evenzeer, dat het irrelevant is of het aantal der gecontroleerde posten groot of klein is. Het streven moge zijn het aantal zo klein mogelijk te houden, het doel is wel daarmede een belangrijk deel van het controlebelang te omvatten (niet van het te controleren bedrag in alle gevallen). De bepaling vooraf van het controlebelang heb ik in mijn publikatie van 1954 gebruikt, waar ik - als gezegd - voor de controle van de omvang van de inkoop de beperking leg op de weinige en waardevolle hoofdmaterialen, welke in de kwantitatieve goederenbeweging domineren; daarnaast de controle op de kwantitatieve omvang van het groot aantal gering-waardige bijmaterialen afleid uit de relatie, waarin het producerend verbruik der hoofdmaterialen het verbruik van bij-materialen vereist. Veelal zal dat betekenen, dat de controle een relatief groot geldbedrag omspant, ondanks sterke beperking van het aantal posten. Ik kan mij echter voorstellen dat er gevallen zijn, waarin het controlebelang niet spoort met het totaalbedrag der goederenbeweging.

De „80-20\% rule”, bekend uit vele Amerikaanse boeken, is dan ook maar een globale bepaling. Dat het - zoals mijn opponent schrijft - in de methode De Wolff - onder bepaalde verhoudingen - irrelevant kan zijn of de gecontroleerde posten tezamen al dan niet een belangrijk deel van het te controleren bedrag uitmaken zou een verschil kunnen zijn met de classificatie ter beperking van de omvang der controle. Om dit te preciseren zou ik moeten weten welke die voorwaarden zijn.

Echter - en daarin moge ik mijn visie op het vraagstuk als in september 1961 gegeven samenvatten - al ware er geen verschil dan nog blijf ik het belangrijk achten of een beperking in de omvang van het controlewerk op ervaringsgrondslagen wordt toegepast dan wel - met behulp van De Wolff's techniek - een stevige wetenschappelijke grondslag heeft.

De heer Van Heerden naar ik in de aanvang van dit stuk citeerde legt mij een eindconclusie in de mond (pag. 457), welke de „methode De Wolff terugwijst tot een heldere formulering van iets wat wij al lang wisten". Dit is niet alleen naar de inhoud onjuist maar zelfs naar de letter een door mijn opponent gewijzigde eindconclusie. Ik heb geschreven (1961 pag. 324) ,Ik erken, dat hij (mijn ambtsgenoot) met zijn uiteenzetting op heldere wijze de betekenis heeft getoond van een werkmethode voor een deel van het controleprogramma, welke wij te veel op ervaringsgrondslagen alleen hebben toegepast". Die twee expressies lijken iets op elkaar in enkele woorden; de betekenis - hetgeen gezegd wordt - is heel iets anders.

Mijn opponent weet even goed als ik, dat de mensen in de techniek van de klassieke oudheid en vroege middeleeuwen toepassingen hebben gebruikt welke wij thans kunnen berekenen. Wij hebben geleerd dat, hadden zij niet toegepast wat de huidige ingenieur-architect berekent, wij de koepels van het Pantheon in Rome en van de Aya Sophia in Istanboel niet meer konden bewonderen. 